\title{
IG \\ P \\ The Consequences of Friendships: Evidence on the Effect of Social Relationships in School on Academic Achievement
}

J ason M. Fletcher

Stephen L. Ross

Yuxiu Zhang

Working Paper

$2019-043$

$07 / 2019$ 


\title{
The Consequences of Friendships: Evidence on the Effect of Social Relationships in School on Academic Achievement
}

\author{
Jason M. Fletcher, ${ }^{\text {a }}$ Stephen L. Ross, ${ }^{\text {}}$ Yuxiu Zhang ${ }^{\mathrm{c}}$
}

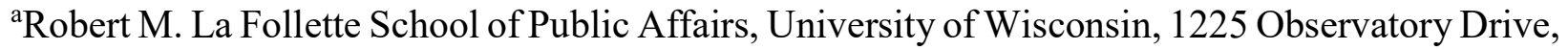
Madison, WI 53706, jfletcher@1afollette.wisc.edu.

${ }^{\mathrm{b}}$ Corresponding author, Department of Economics, University of Connecticut, Storrs, CT 062691063, stephen.1.ross@uconn.edu, (860) 486-3533.

'Genentech, 1 DNA Way Mailstop 258A, South San Francisco, CA 94080, yuxiu909@gmail.com

Abstract: This paper examines the impact of youth friendship links on student's own academic performance (grade point average) using the Add Health. We estimate a reduced form, high dimensional fixed effects model of within cohort or grade friendship links, and use this model to predict each student's number of friends whose mothers have a four year college degree. The effects of friendship links are identified using across-cohort, within school variation in demographic composition of the student's cohort or grade. We find that increases in number of friendship links with students whose mothers are college educated raises grade point average among girls, but not among boys. Additional analyses suggest a positive view of the school environment and a perception of one's self as functioning well in that environment as possible mechanisms. The effects are relatively broad based across students over maternal education, racial and ethnic composition and across schools that vary in demographic composition over the same variables.

Key Words: Social Interactions; Friendships; Heterogeneous Peer Effects; Grades; Cohort Study; Non-Cognitive Effects.

JEL Codes: I21, J13, R23.

Disclaimer: The content is solely the responsibility of the authors and does not necessarily represent the official views of the National Institutes of Health $(\mathrm{NIH})$. This research uses data from Add Health, a program project directed by Kathleen Mullan Harris and designed by J. Richard Udry, Peter S. Bearman, and Kathleen Mullan Harris at the University of North Carolina at Chapel Hill.

Funding: Research reported in this publication was supported by the Eunice Kennedy Shriver National Institute of Child Health \& Human Development (NICHD) of the National Institutes of Health (NIH) under Award Number R21HD066230. 


\section{The Consequences of Friendships: Evidence on the Effect of Social Relationships in School on Academic Achievement}

\section{Introduction}

Economists have long been interested in whether the outcomes of individuals are shaped by their interactions with those around them. A special focus has often been placed on the effect of environment on children since the have less control over their environment and because these environmental effects may have impacts on intergenerational mobility. A large literature documents the effect of school peers on student outcomes using quasi-experimental variation across cohorts of students (Lavy, Paserman and Schlosser 2012; Bifulco, Fletcher and Ross 2011; Lavy and Schlosser 2011; Friesen and Krauth 2011; Hanushek, Kain and Rivkin 2009; Hoxby 2000). The evidence on exposure to neighborhoods is more mixed. Oreopoulos (2003), Jacob (2004), Kling, Liebman and Katz (2007) and Ludwig et al. (2013) find minimal effects of neighborhood using experimental and quasi-experimental evidence on the mobility of public housing residents. More recently, Chetty, Hendren and Katz (2015) find long-run effects for the youngest children of movers out of public housing, and Chetty and Hendren (2015) find evidence of neighborhood effects comparing children within the same families who were different ages when they moved. ${ }^{1}$

Many studies suggest that social interactions are an important mechanism behind peer and neighborhood effects at least in part by showing that peer and neighborhood spillovers are larger when individuals are more similar on economic and demographic attributes. Bertrand, Luttmer and Mullainathan (2000) find evidence that residing near individuals who speak the same language as oneself raises welfare usage for members of language groups that have a high rate of welfare

\footnotetext{
${ }^{1}$ See Ross (2011) for a survey of the peer and neighborhood effects literature.
} 
participation. Bayer, Ross and Topa (2008) find that individuals have better labor market outcomes when their immediate neighbors are similar in education, age, gender, marital status and age of children. Bayer, Hjalmarsson and Pozen (2009) show that criminal peer effects are stronger when juveniles who have similar criminal expertise are grouped together in correctional facilities. Hellerstein, McInerney and Neumark (2011) find that same race and ethnicity employees at the same firm are more likely to come from the same neighborhood relative to employees who just work in the same location. Haskell (2015) finds that students' who are more demographically distance from their cohort peers engage in riskier behavior and have worse social and emotional outcomes. Billings, Deming and Ross (2016) show that residential exposure to nearby peers who are of the same age, race and gender increases the likelihood of committing a crime when the individuals attend the same school.

However, these quasi-experimental, reduced form studies typically do not have any direct information on whether the individuals in the school or neighborhood interact socially, share information or have other contacts. ${ }^{2}$ In one clear exception, Air Force Academy students were assigned to groups intended to maximize the performance of the lowest ability students based on previous evidence of peer effects in this population (Carrell et al. 2009). However, Carrell, Sacerdote and West (2013) find an unexpected negative effect on the treatment group, apparently because after the experiment students in treated squadrons tended to self-segregate into subgroups

\footnotetext{
${ }^{2}$ Billings, Deming and Ross (2016) represent an exception because they observe whether individual students were arrested for committing crimes together. Also see Fisman et al. (2008) on speed dating. A large structural literature also exists empirically examining the effects of networks on economic outcomes. See for example Calvó-Armengol, Patacchini, and Zenou (2009), Patachini and Zenou (2012), and Bramoulle, Djebbari and Fortin (2009). These models have in some cases been identified by assuming social network structure is exogeneous or assuming that the unobservables of the friend's of a student's friends are uncorrelated with the students unobservables, after conditioning on the friend's observables.
} 
based on ability. This study documents that social interactions and relationships between individuals can be a critical component in generating positive or negative peer effects. ${ }^{3}$

In this study, we estimate whether having friends whose mothers have a four-year college degree affects a student's Grade Point Average (GPA) using one of the only data sets that both contains information on social relationships and supports quasi-experimental analyses of peer effects, the National Longitudinal Study of Adolescent Health (Add Health). ${ }^{4}$ Specifically, we estimate a non-parametric, reduced form model of within grade and school friendship links using high dimensional fixed effects across schools and exploiting the demographic match between students of different types based on race and maternal education. Using the friendship link model estimates and the set of same gender-same grade potential friends, we predict the maternal education composition of each students' friends so that, for a given student type, predicted friendship composition only varies across cohorts/grades based on across cohort variation in demographic composition. Critically, the fixed effect estimates used for one cohort of students omits that cohort from the estimation so that the predicted friendship patterns of the students in a specific grade and school is not influenced by the within grade friendship choices of those students. The across cohort variation in predicted friendships with students of high maternal education is strongly predictive of actual friendships, and the prediction appears orthogonal to a relatively broad set of student demographics.

We then regress grade point average on predicted friendship composition conditional on fixed effects for school-by-student-type and school-by-cohort. This model follows a difference-

\footnotetext{
${ }^{3}$ Similarly, Weinberg (2007) develops a model in which peer effects are non-linear and vary across individuals because students can sort within peer groups. Weinberg (2013) exploits a similar model to examine the optimal composition of broad peer groups in order to facilitate integration in social relationships within those groups.

${ }^{4}$ Maternal education was identified as an important peer attribute for explaining student outcomes in the Add Health sample by Bifulco, Fletcher and Ross (2011).
} 
in-differences structure because predicted friendship composition is based on combining information on friendship patterns that are estimated at the school by student type level and friendship opportunities that are measured at the school by cohort level. We find that having more friends whose mothers have a four year college degree is associated with better academic grades for female students. ${ }^{5}$ One additional friend whose mother has a college degree implies a 0.204 grade point increase in GPA, which is about an 8 percent increase at the mean GPA of 2.71 for all female students and represents a 0.25 standard deviation increase. A one standard deviation increase in the number of friends of this type is associated with a 0.17 standard deviation increase in GPA. We do not find statistically significant effects for male students, but the estimates are noisier and we cannot rule out friendship effects for males.

As with Carrell, Sacerdote and West (2013), we cannot prove that friendship patterns are responsible for the differences in grades because the demographic environment of a cohort of students that facilitates such friendships potentially could cause the effects on GPA. However, our model specification and other tests rule out traditional cohort level peer effects even if those effects are heterogenous across students. Further, our results complement those of Carrell, Sacerdote and West (2013) providing a second strong piece of evidence that the effect of exposure to the peer environment is highly correlated with the types or extent of social relationships facilitated by that peer environment.

Further, our paper contributes additional quasi-experimental evidence on the effect of friendships on academic outcomes. There exists very limited quasi-experimental evidence on

\footnotetext{
${ }^{5}$ Several peer effect studies have found that effects differ by gender including Argys and Rees (2008), Bifulco, Fletcher, Oh and Ross (2013), Black, Devereux, and Salvanes (2010) and Hseih and Lin (2017). Our specific results are in line with several papers that have produced evidence of gender-based peer effects on labor market outcomes. For example Olivetti et al. (2013) find associations between adolescent peers mother's labor supply decisions and own outcomes for women; Mota et al. (2016) show evidence of similarity in women's labor force decisions between neighbors with similarly aged children. In each case, there was no similar effect for men.
} 
effects of friendships on youth outcomes. ${ }^{6}$ Fletcher and Ross (2018) examine the spillover effects of friends' smoking and drinking finding large increases in these behaviors in response to the behavior of friends. Lavy and Sand $(2013,2018)$ examine the effects of being separated from friends during a transition between schools, and find negative effects on test scores and other measures of student well-being. Billings, Deming and Ross (2016) show that student residing very near other are more likely to be arrested together for a crime if they are assigned to the same school attendance zone. ${ }^{7}$ To our knowledge, these are the only three studies that provide evidence of spillovers across friendships or social relationships based on exploiting quasi-randomness in student or youth assignments to grades or schools. ${ }^{8}$

\section{Empirical Model}

Friendships patterns are characterized by homophily (Weinberg, 2007, Moody 2001), and the demand for homophily might vary based on a school or school's demographic composition. In a school with more minority students, the value of friendships with minority students might be higher because the tendency towards homophily implies greater popularity among minority students as their representation increases. ${ }^{9}$ Alternatively, increases in minority share may lead to

${ }^{6}$ Weinberg (2007) and Mayer and Puller (2008) show that students tend to associate with individuals like themselves, which may mitigate the impact of peer composition. Marmaros and Sacerdote (2006) examine the predictors of email contact among Dartmouth students. Neither paper exploits quasi-experimental variation. Also see Lichter (2013).

${ }^{7}$ See Conti, Galeotti, Muller, and Pudney (2013) for a recent study that provides more traditional evidence on the impact of friendship nominations using individual level exclusion restrictions.

${ }^{8}$ A small, but growing, number of studies develop structural models of productive social networks with endogenous network formation including Currarini, Jackson, and Pin (2009), Badey (2013), Goldsmith-Pinkham and Imbens (2013), Graham (In Press), Lui, Patachinni, Zenou and Lee (2014) and Hseih and Lin (2017); however, parameters are usually not identified from quasi-experimental variation. Some of these studies exploit the strategy of using the behaviors or attributes of friend's friends as instruments for friend's behaviors or attributes, as in Bramoullé, Djebbari and Fortin (2009).

9 Ballester, Calvó-Armengol, and Zenou (2006) and Calvó-Armengol, Patacchini, and Zenou (2009) consider models where the gains from friendship depends upon network centrality. 
increased polarization between groups or simply increase the number of same-race friendship candidates and crowd out across-race friendships.

We develop an empirical model of within-grade friendship links based on the race, ethnicity and the education of the student's mother. Race and ethnicity are included in the model due to the strong patterns of friendship homophile documented in the existing literature. ${ }^{10}$ As a second variable, we also include maternal educational attainment because we are explicitly interested in the effects of having friend's with different levels of maternal education on student academic outcomes and in part because maternal education is our best measure of "social class" in our data. We divide students into cells based on students having the same race, ethnicity and maternal educational attainment. We model the observed patterns of friendship links using a nonparametric specification within each school based on high dimensional fixed effects associated with each possible combination of same grade, same gender students based on the cells above. We focus on within grade friendships, which represent $83 \%$ of same-sex nominations in our sample. Students of a given race, ethnicity or maternal education may sort into schools through parents' choices, but are assumed to be distributed quasi-randomly across the cohorts/grades within any school. ${ }^{11}$

In modeling within grade, within gender friendships, every student may form a friendship with any same gender student in his/her grade or cohort $c$ within school $s$, and our student level data is arranged as a sample of pairs of same-grade, same-gender students $i$ and $j .{ }^{12}$ Students are categorized into one of $x$ nominal "types", where a type is defined as an observationally equivalent cell based on the race/ethnicity and the family background (maternal educational attainment) of

\footnotetext{
${ }^{10}$ See Weinberg (2007) and Moody (2001) for example.

11 This assumption is supported by balancing tests conducted here and in Bifulco, Fletcher and Ross (2011).

${ }^{12}$ If a cohort has $n_{c s}$ students of a given gender, then that population of students will contribute $n_{c s}\left(n_{c s}-1\right) / 2$ total observations to our sample where pairs are non-directional.
} 
each student. The pair of students of type $x$ and type $y$ is defined as $\{x, y\}$. A self-reported link between students $i$ and $j\left(P_{i j x y c s}\right)$ is a binary outcome that depends upon the quality of the match between students.

$$
\mathrm{P}_{\mathrm{ijxycs}}=\delta_{\mathrm{xys}}+\pi_{c}+\mu_{\mathrm{ijxycs}}
$$

where $\delta_{x y s}$ is a pair-type-by-school fixed effect that allows for non-parametric patterns of friendship formation because pair type enumerates all observationally equivalent pairs of students based on race, ethnicity and maternal education, and $\pi_{c}$ is a cohort/grade fixed effect. Finally, $\mu_{i j x y c s}$ is a stochastic return to the match between students, which might include each student's unique propensity to form friendships.

Using our friendship formation model, we develop predictions of friendship composition for each individual type (observationally equivalent students over maternal education and race/ethnicity) in each cohort and school. For individual $i$ of type $x$, the expected number of friends of type $y$ is based on summing equation (1) over all individuals of type $y$ in the cohort and dropping the unobservable.

$$
\overline{\mathrm{p}}_{x C S}^{y}=\sum_{\mathrm{j} \neq \mathrm{i}, \mathrm{j} \in\{\mathrm{y}, \mathrm{c}, \mathrm{s}\}}\left(\delta_{\mathrm{xys}}\right)
$$

These predictions vary across demographic groups within cohorts because the likelihood of friendship formation differs based on $\delta_{\mathrm{xys}}$ and vary across cohorts for the same student type because cohort differences in composition change the opportunity set of potential within cohort friends. $^{13}$

In practice, we must use an estimate of $\delta_{\mathrm{xys}}$, and given potentially small demographic cells within schools an individual's own friendship decisions or the decisions of others who interact

\footnotetext{
${ }^{13}$ We omit the estimates of the cohort fixed effects in equation (1) from our prediction for parsimony of presentation because those estimates have no effect given the fixed effect structures used in the models to follow.
} 
with this individual may have an undue influence on the fixed effect estimate. Therefore, we predict the number of type $y$ friends for students in cohort or grade $c$ omitting all students in cohort $c$ from the estimation, and use this omit own cohort estimate $\hat{\delta}_{x y s}^{-c}$ to predict the probabilities.

$$
\hat{P}_{x c s}^{y,-c}=\sum_{\mathrm{j} \neq \mathrm{i}, \mathrm{j} \in\{y, c, s\}}\left(\hat{\delta}_{x y s}^{-c}\right)
$$

This strategy is similar to "leave-one-out" instrumental variable approaches used in Angrist, Imbens and Krueger (1999) and Blomquist and Dahlberg (1999). ${ }^{14}$

Next, consider a model where a student $i$ of type $x$ 's outcome $Y_{\text {ixcs }}$ may be influenced by the type of friendship links formed by the student:

$$
\mathrm{Y}_{\mathrm{ixcs}}=\theta p_{i x c s}^{y}+\gamma_{\mathrm{xs}}+\mathrm{v}_{\mathrm{cs}}+\tau_{\mathrm{ixcs}}
$$

where $p_{\text {ixcs }}^{y}$ is number of friends of type $y, \gamma_{x s}$ is a vector of school by student type fixed effects, $\mathrm{v}_{\mathrm{cs}}$ is a vector of school-by-cohort fixed effects and $p_{i x c s}^{y}$ potentially correlates with the unobservable $\tau_{i x c s}$.

We instrument for $p_{i x c s}^{y}$ by estimating a model that controls for the individual level prediction of friendship composition $\hat{P}_{x c s}^{y,-c}$ plus the school by type and cohort by school fixed effects. An additional control measured at the cohort level, $\hat{\mathrm{q}}_{\mathrm{xcs}}^{\mathrm{y}}$, addresses bias that arises from omitting an individual's own contribution or the contribution of a larger group to which the individual belongs when constructing aggregate variables (Bayer, Ross and Topa 2008; Guryan, Kroft and Notowidigdo 2009).

$$
p_{i x c s}^{y}=\omega_{1} \hat{\mathrm{p}}_{\mathrm{xcs}}^{\mathrm{y},-\mathrm{c}}+\omega_{2} \hat{\mathrm{q}}_{\mathrm{xcs}}^{\mathrm{y}}+\varphi_{\mathrm{xs}}+\eta_{\mathrm{cs}}+\rho_{\mathrm{ixcs}}
$$

\footnotetext{
${ }^{14}$ We thank Kevin Lang for pointing this out.
} 
The precise construction of this control and a comparison to the control function developed in Guryan, Kroft and Notowidigdo (2009) is provided in Appendix A. ${ }^{15}$ Note that in principle $\hat{p}_{\mathrm{xcs}}^{\mathrm{y},-\mathrm{c}}$ could be a vector of predicted compositions. In practice, $\mathrm{p}_{\mathrm{ixcs}}$ for a single friendship attribute is regressed on $\hat{p}_{x c s}^{y,-c}$ and $\hat{q}_{x c s}^{y,-c}$ for the same demographic trait, e.g. number of friends whose mothers have a college education.

Next, we obtain consistent estimates of $\theta$ using a second stage estimation equation

$$
\mathrm{Y}_{\mathrm{ixcs}}=\theta \hat{\mathrm{p}}_{\mathrm{ixcs}}^{\mathrm{y}}+\pi \underline{\hat{\mathrm{q}}}_{\mathrm{xcs}}^{\mathrm{y}}+\gamma_{\mathrm{xs}}+\mathrm{v}_{\mathrm{cs}}+\tau_{\mathrm{ixcs}}
$$

where $\hat{\mathrm{p}}_{\mathrm{ixcs}}^{\mathrm{y}}$ is the predicted value from equation (5). ${ }^{16}$

Unlike Bifulco, Fletcher and Ross (2011) who simply included school fixed effects, our model includes school by student type fixed effects. These fixed effects absorb any effects or correlates of schools that vary across the type of student including heterogenous effects of peers at the school level and variation that arises because selection into the school might vary based on student race, family background or past behavior. Therefore, equation (6) is only identified using across cohort comparisons of demographically identical students over type $x$. Further, our model includes school by cohort fixed effects that capture any homogenous peer or environmental effects at the grade or cohort level. As noted above, the resulting model is basically a difference-in-

\footnotetext{
${ }^{15}$ Appendix A is presented at the end of the paper. Note that while Guryan, Kroft and Notowidigdo (2009) consider bias associated with peer group means in balancing tests, their arguments apply to conditional means, such as predicted values from regressions, and any regressions using such means, not just balancing tests.

16 This model is quite different from models discussed in Angrist (2014). Angrist considers a model where an individual attribute like SAT score is replaced in a regression by the average attribute of a group, and the test for peer effects is whether the average attribute has some explanatory power over and above the individual attribute. Angrist makes two important points: 1. the group average can be viewed as an instrument for the attribute and so the test for peer effects is whether the IV estimate exceeds the OLS estimate, and 2. with random group assignment the instrument is likely weak so this test requires the assumption that the IV and OLS estimates be the same under the null hypothesis of no peer effects. In our case, the individual attribute is number of friends of a certain type, and we measure the conditional mean of that attribute for a group of same type, school and cohort students. However, we are not testing for the excess effect of the group mean over the actual attribute, but rather instrumenting for an endogenous individual attribute. Further, based on the F-statistics below our instruments are not weak.
} 
differences analysis where the first difference arises by comparing observationally equivalent individuals in different cohorts of the same school, and then the second difference is between cohorts for different types of students where the differences in outcomes between cohorts should be larger for the types of students where the difference in the predicted number of friends is largest.

Given that predicted numbers of friends only vary by student type-cohort-school, we can convert this model to a triple difference model simply by adding fixed effects for student type by cohort or

$$
\mathrm{Y}_{\mathrm{ics}}=\theta \hat{\mathrm{p}}_{\mathrm{ixcs}}^{\mathrm{y}}+\pi \underline{\hat{q}}_{\mathrm{xcs}}^{\mathrm{y},-\mathrm{c}}+\gamma_{\mathrm{xs}}+\mathrm{v}_{\mathrm{cs}}+\omega_{x c}+\tau_{\mathrm{ics}}
$$

The triple difference estimates basically compare the difference-in-differences estimates across schools testing for larger difference-in-differences estimates in schools where the differences between student types in across cohort differences in predicted number of friends are largest. We focus on the difference-in-differences estimates because they are more intuitive, and present the triple difference estimates for the baseline model as a robustness test. However, all results presented in the paper and appendix have been replicated using the triple difference estimator.

\section{Data}

The Add Health surveyed schools with school sizes between 44 and 2,418 students containing students between grades 7 through 12. For each high school in the survey, ${ }^{17}$ a middle school whose students tended to feed into this high school was identified and also surveyed. For this analysis, we create pseudo schools by combining each high school with the middle school feeder that was surveyed so that friendship patterns can be documented for six grades/cohorts of students in each pseudo school. This reorganization leads to a sample of 87 pseudo schools that

\footnotetext{
${ }^{17}$ With the exception of a few smaller combined middle-high schools. Note that even if a middle school contained a $6^{\text {th }}$ grade those students were not surveyed.
} 
we label as "schools" for brevity. ${ }^{18}$ We focus on the "In-School" sample of over 90,000 students (virtually all students) at sample schools in the 1994-95 academic year. The survey collected data on socio-demographic characteristics, health status, risk behaviors, academic achievement, and friendship nominations. After several sample restrictions for technical reasons, we have a final sample of $87,006 .^{19}$

Each student was asked to identify up to five male and five female friends that attended the same school, and these "friends" are linked by name to the other surveyed students. Like much previous work, we focus on same-gender friendships in this sample to separate "friends" from “romantic relationships". We also focus on within grade friendship ( $83 \%$ of same-sex friendships) in order to identify the effect of peer composition using across cohort variation. ${ }^{20}$ We analyze mutual friendship or reciprocal links, meaning two students are friends if they both nominated each other, since presumably relationships in which both parties agree on the friendship are stronger (Goodreau, Kitts and Morris 2009). ${ }^{21}$ In addition, mutual acknowledgement of friendship rules out nominations that reflect aspirational preferences. ${ }^{22}$ Another interpretation of using mutual

\footnotetext{
${ }^{18}$ When middle and high schools could not be matched, the individual schools were treated as their own school or cluster for the purpose of the analysis, rather than dropping observations.

${ }^{19} 178$ individuals were dropped from the sample due to missing identification numbers, who were likely new students and not yet on the school roster; another 2,637 are dropped because of missing grade, race, sex, or missing the majority of their friendship information; we exclude the twin sample, which contains 2,492 students; 400 observations are dropped because they have assigned grades that do not match the grades associated with that school (e.g. a $7^{\text {th }}$ grader in a high school that primarily contains $9^{\text {th }}-12^{\text {th }}$ graders); and we exclude 49 observations from small schools (less than 10 students per grade/cohort on average).

${ }^{20}$ We regressed our cohort variables on whether individuals nominate friends outside of their grade with schoolgender fixed effect, and found no correlation

${ }^{21}$ Goodreau, Kitts and Morris (2009) explain the focus on mutual friendship as follows: "mutual friendships are cross-validated and are likely to be stronger than one-way friendship nominations. Focusing on mutual ties may thus reduce the truncation induced by the cap on five nominations...".

${ }^{22}$ The average numbers of identifiable same-gender friends nominated are 2.65 for male students and 3.10 for female students, and very few students reach the survey cap of 5 friends. However, most nominations are onedirection. On average, a male has 0.69 and a female has 1.10 mutual friends.
} 
friendship nominations is a focus on "best friends" rather than acquaintances. ${ }^{23}$ Both bidirectional and single direction friendship links capture actual friendship patterns with error, but measurement error in the left-hand side variable is not a source of bias in the friendship match model. Further, in the second stage analysis on the effect of friendships, our instrumental variables strategy insulates us against bias from measurement error in actual friendships.

Table 1 shows basic friendship patterns over maternal education and race/ethnicity, i.e. the fraction of same-gender/same-grade friendships in each maternal education or race/ethnicity category by the students' own category. Maternal education levels are divided into four categories: no high school degree, high school graduate, graduate with a four year college degree, and maternal education missing. ${ }^{24}$ Race/ethnicity is captured by non-Hispanic white, non-Hispanic black, Hispanic and other race, where the other category is primarily Asian or Pacific Islander. Columns (1) and (4) indicate the average number of friends that a student of a certain category has; columns (2) and (5) show the share of friends coming from the students' own category; columns (3) and (6) provide the sample shares of each group. The table shows substantial homophily in friendship patterns. The percent of friends with the same maternal education as the student always exceeds the fraction of students in the population with the largest differences arising for students whose mothers either did not graduate from high school or are college educated where the fraction of same group friends is nearly double the share in the population. Homophile is even more pronounced over race and ethnicity with share of own race friends typically 3 to 4 times the representation in the population for blacks, Hispanics and other race students. In terms of gender,

\footnotetext{
${ }^{23} \mathrm{We}$ also examine link models based on one-way friendship links, and the resulting estimates are qualitatively similar, but smaller in magnitude consistent with one way links being less important than friendships identified where both individuals claim each other as friends.

${ }^{24}$ Appendix Table 1 presents the same means by gender.
} 
black and Hispanic female students and female students whose mothers are not college educated exhibit higher levels of homophily than comparable males.

Maternal education is not reported for approximately 20 percent of the sample, and we create a separate "missing" category for those students. While students may not randomly select into this category, it is notable that the likelihood of a maternal education missing student having a maternal missing friend is very close to the population average so we do observe assortative matching on student's own missingness in maternal education. Further, we rely on our nonparametric controls to capture students sorting into schools by type, including maternal education missing. ${ }^{25}$

In order to create the student friendship link sample, we form a sample of all possible, nondirectional pairs between students from the same grade and of the same gender for every school. The resulting matched sample contains about 6 million potential links. The outcome is a binary variable indicating whether the two parties in a pair nominated each other as a friend. As discussed above, we defined four racial and ethnic categories (non-Hispanic white, non-Hispanic black, Hispanic, and Asians/Other race) ${ }^{26}$ and four maternal education categories (four-year college degree, high school graduate, no high school degree, and maternal education not reported). This implies $10 \mathrm{racial} / \mathrm{ethnic}$ combinations for a pair of students $(\mathrm{N}(\mathrm{N}+1) / 2=4(4+1) / 2=10)$ and 10 maternal education combinations. Further, race/ethnicity and maternal education together define 16 student types. This results in 136 potential student-pair combinations (fixed effects) for each gender and

\footnotetext{
${ }^{25}$ Our analyses are reduced form, and we obtain the causal effects of exposure to students of each type including education missing. Both our balancing tests and our estimates of friendship effects are robust to how we treat students for which maternal education is missing. Later in the paper, we also present robustness tests that modify how we handle students where maternal education is missing.

${ }^{26} 56 \%$ in this group self-identify as Asian, and results are robust to omitting non-Asians.
} 
school. ${ }^{27}$ The fixed effects are estimated using linear probability models. The resulting predicted friendship composition variables are merged back into the student level data by school, grade/cohort, gender and student race, ethnicity and maternal education type.

Table 2 shows the means of student variables where we divide the sample by whether the student has zero versus one or more friends whose mothers have a four year college degree. Panel 1 presents outcome variables demonstrating that GPA increases modestly and number of friends whose mothers have no high school degree decreases modestly with maternal education level of friends. Panel 2 shows the student demographics that are exploited for predicting friendship patterns, Panel 3 shows the demographics used in the balancing tests below, and Panel 4 shows the means over school attributes. ${ }^{28}$ Students with friends who have college educated mothers are more likely to be female, be white, have a mother who completed college, live with both parents, live in households that have less kids, and be born in the U.S. They are also more likely to attend schools that have a higher percentage of white students, have a higher share of maternal college mothers, and are larger.

\subsection{Evidence Supporting the Research Design}

Our maintained assumption is that students are quasi-randomly sorted into cohorts, and if this assumption holds then the predicted friendship patterns should be uncorrelated with the attributes of the individual conditional on the school by student type fixed effects. We conduct student level balancing tests to validate that assumption by selecting demographic variables like nativity or family structure that are not used in the fixed effect vector and regressing predicted

\footnotetext{
${ }^{27} \mathrm{~N}(\mathrm{~N}+1) / 2=(16 * 17) / 2=136$. One example is white-dropout/white-college, indicating that one student is white with a high school dropout mom, and the other is white with a college graduate mom.

${ }^{28}$ Note that one of the variables used in the balancing test is years of maternal education because years of education can vary within our maternal education attainment cells.
} 
friendship patterns on these attributes. If an attribute is missing, the variable is set to zero and a dummy variable is included that takes on the value 1 whenever this particular variable is missing.

The first balancing test uses the entire student sample and conducts a traditional cohort balancing test regressing cohort composition over maternal education, race and ethnicity after omitting a student's own contribution $\left(Z_{i c s}^{-i}\right)$ on ten exogenous attributes of students $\left(X_{\text {ics }}\right){ }^{29}$

$$
Z_{i c s}^{-i}=\alpha X_{\mathrm{ics}}+\varphi_{\mathrm{gs}}+\phi_{\mathrm{c}}+\xi_{\mathrm{ics}}
$$

where $X_{\mathrm{ics}}$ is the vector of attributes, $\varphi_{\mathrm{gs}}$ are actual school (high school or middle school) by gender fixed effects and $\phi_{c}$ are cohort or grade fixed effects. These results are shown in Table 3 Panel 1. Each column in Table 3 Panel 1 represents a single regression relating cohort composition to individual demographics and presents the F-tests for the full set of demographic coefficients in the regression. All F-tests are statistically insignificant, and cohort shares cannot be explained by the predetermined student attributes. ${ }^{30}$ Further, we calculate the R-squared of the balancing test variables conditional on the fixed effects by calculating first the R-squared with and without the balancing test controls and then dividing the improvement in the R-squared from adding the balancing test controls by the variance that was not explained by the fixed effects alone (one minus the R-squared without controls). This ratio is presented in the row labelled within R-squared, and we find that the balancing test variables explain less than one-tenth of one percent of the remaining variation in the cohort compositions. ${ }^{31}$

\footnotetext{
${ }^{29}$ We follow Billings, Deming and Rockoff (2012) by placing the cohort composition on the left-hand side and conduct an F-test test for whether the set of exogenous attributes systematically explains cohort composition. The results are nearly identical if we do not omit the individual since on average a single person is only a small part of the cohort of students to which they belong.

${ }^{30}$ See Appendix Table 2. All individual coefficients are insignificant. Note that years of maternal education can be included in the balance test because the fixed effects control for discrete levels of educational attainment.

${ }^{31} \mathrm{We}$ also pass balancing tests on share students with maternal education missing and show that cohort variables are uncorrelated with students nominating friends outside of his/her own grade.
} 
Next, we conduct a balancing test using the regression sample and our constructed variables for predicted number of friendships of a given type.

$$
\hat{\mathrm{p}}_{\mathrm{xcs}}^{\mathrm{y},-\mathrm{c}}=\alpha X_{\mathrm{ixcs}}+\pi \underline{\hat{\mathrm{q}}}_{\mathrm{xcs}}^{\mathrm{y},-\mathrm{c}}+\varphi_{\mathrm{xs}}+\phi_{\mathrm{cs}}+\xi_{\mathrm{ixcs}}
$$

where again $X_{\text {ics }}$ is the vector of attributes, $\underline{\mathrm{q}}_{\mathrm{xcs}}^{\mathrm{y},-\mathrm{c}}$ is our control function for the omission of own cohort from $\hat{\mathrm{p}}_{\mathrm{xcs}}^{\mathrm{y},-\mathrm{c}}, \varphi_{\mathrm{xs}}$ is the vector of student type by school fixed effects and $\phi_{\mathrm{cs}}$ is the vector of cohort by school fixed effects. ${ }^{32}$ In Table 3 Panel 2, we present the estimates for these models where columns 1 and 2 present the F-tests for the female sample on predicted number of maternal college friends and maternal no high school degree friends, respectively. Columns 3 and 4 present the same analysis for the male sample. Again, the F-tests are statistically insignificant, ${ }^{33}$ and the variables explain less than one-tenth of one percent of the variance after conditioning on the fixed effects.

For comparison, we estimate these models in Panel 3 for actual number of maternal college friends using the full sample and strongly reject the independence of actual friendships. ${ }^{34}$ This exercise illustrates that actual friendship pattern differences across cohorts are highly correlated with student demographics, but our instrumental variable strategy is successful in eliminating this correlation. Unlike in panel 2, the resulting F-statistics are substantial in magnitude and statistically significant. Similarly, the within fixed effects R-squareds in panel 3 are an order of magnitude

\footnotetext{
32 The regression sample is restricted to the 73,840 students who self-report their Grade Point Average on the inschool survey conducted in wave 1 . This sample also includes a restriction dropping 223 observations that belong to singleton student type by school clusters.

${ }^{33}$ See Appendix Table 3. Again, virtually all individual estimates are statistically insignificant. Balancing tests yield estimates even closer to zero with even smaller F-tests if we do not include the term $\hat{\mathrm{q}}_{\mathrm{xcs}}^{\mathrm{y}, \mathrm{c}}$ consistent with Guryan, Kroft and Notowidigdo (2009)'s conclusion that omitting own cohort biases results towards finding balance and that the control function eliminates that bias.

${ }^{34}$ Panel 2 restricts the sample to be the same as regression sample used in the next section to demonstrate balance for the same model and sample. There is no reason to impose this restriction in panel 3, but when the sample restriction is imposed the results are very similar. Finally, the regressions in Panel 3 do not include the control function for the omission of own cohort since actual friendships are used as the dependent variable.
} 
larger than those in panel 2 for the maternal college graduate models and 2 to 4 times larger for the maternal no high school models. Finally, comparing the individual estimates in Appendix Table 3 for the predicted friendship patterns and Appendix Table 4 for the actual friendships shows estimates in Appendix Table 4 that are often an order of magnitude larger than the estimates in Appendix Table 3.

\section{Results}

In columns 1 and 5 of Table 4, we show that our predicted friendship composition measures are strongly related to the actual friendship nominations with t-statistics over 10 for number of maternal college friends and over 6 for number of maternal no high school degree friends. Looking at the IV regressions in columns 3, 4, 7 and 8. The associate F-statistics from the test for weak instruments always exceeds 10 and is around 100 for maternal college and between 30 and 40 for maternal non-high school graduate. ${ }^{35}$ The OLS coefficients for Grade Point Average (GPA) from columns (2) and (6) show that students having more friends with a college educated mother have higher GPA relative to their cohort/grade mates, but having more friends whose mom dropped out of high school is unrelated to GPA.

In Columns 3, 4, 7, 8, we examine friendship composition effects for GPA using two-stage least squares. We test one "type" of friendship at a time. For example, in columns (3) and (7), we regress GPA on the predicted number of friends with a college graduate mom. The IV estimates differ from OLS estimates. The coefficient of college graduate mom increases by $31 \%$ for female students, but changes from significant and positive to insignificant and small for males. ${ }^{36}$ The

\footnotetext{
${ }^{35}$ In another illustration of the power of the instruments, Appendix Table 5 presents the standard deviations of the instruments and the standard deviation of the instrument residuals after removing the school by type fixed effects and over half the variation in the variables remains in the residuals.

${ }^{36}$ While the IV point estimate is near zero for males, the estimate is significantly noisier than the estimate for females with a standard error that is three times larger than for females, and we cannot rule out substantial friendship effects for males. Further, note that the noisy estimate is not due to differences in the strength of the instrument, but
} 
estimated coefficient of number of friends with college graduate mom is 0.204 for females, indicating that one more mutual friend with a college educated mom is associated with a 0.204 grade point increase of GPA, which is about a 7 percent increase at the mean GPA of 2.88 for all female students and represents a 0.25 standard deviation increase. A one standard deviation increase in the number of friends of this type is associated with a 0.17 standard deviation increase in GPA. The coefficients on dropout in columns (4) and (8) remain small and insignificant.

For comparison purposes, we estimate a model of peer effects examining how the share of students in a cohort whose mothers have a four year college degree affects the GPA of female and males students. We estimate a standard cohort based peer effects model simply controlling for actual school and cohort/grade fixed effects or

$$
\mathrm{Y}_{\mathrm{ics}}=\theta Z_{i c s}^{-i}+\gamma_{\mathrm{s}}+\mathrm{v}_{\mathrm{c}}+\tau_{\mathrm{ics}}
$$

where $Z_{i c s}^{-i}$ is simply the cohort share of students whose mothers have a four year degree omitting the student themselves.

We find peer effect estimates for the share of students whose mothers are college educated of 0.585 with a standard error of 0.210 for girls and a somewhat smaller estimate of 0.499 with a standard error of 0.242 for boys. ${ }^{37}$ This implies that a 10 percentage point increase in the number of maternal college educated students in a cohort leads to a 0.059 increase in GPA for girls and a 0.050 increase for boys. The sample average number of maternal college students is 0.298 (omitting students for whom maternal college is missing). A 10 percentage point increase leads to

instead potentially due to a much noisier process for determining male GPA. The standard errors associated with the effects of friends whose mothers did not complete high school are also always quite large, likely due to the small fraction of students in the population whose mothers did not complete high school and the concentration of this population among Hispanic students.

37 These estimates are presented in Appendix Table 6. The effect for GPA differs from the results of Bifulco, Fletcher, Oh and Ross (2014) who find that share of cohort level peers whose mothers have a college degree only affects college attendance for boys. 
a 0.398 share or a 34 percent increase in the share, and so implies a 34 percent increase in the potential friendship links to maternal college students. Later in the paper, we show that the estimate friendship effects are relatively stable over schools based on the share of maternal college students, and similarly confirm that the first stage friendship predictive model is stable over type of school. ${ }^{38}$ Therefore, as a back of the envelope calculation, we can approximate the effect of increasing the number of potential links with maternal college students by $34 \%$ as an increase in the number of potential maternal college friends by $34 \%$. The estimated effect of such a change on GPA is then simply 0.34 times the average number of maternal college friends of 0.318 times the estimated effect size of 0.204 , or an increase of 0.022 , which is approximately 38 percent of the peer effect estimates for girls and more than double the difference between the estimated peer effects for girls and boys. These effect sizes suggest that friendships play a significant role in observed peer effects for girls.

\subsection{Robustness}

We next examine the robustness of these estimates in Table 5. First, in Panel 1, given that maternal education is missing for a large segment of the population, we re-estimate the models dropping all observations where maternal education is not observed, and then re-estimate the models replacing maternal education with paternal education whenever maternal education is not observed. $^{39}$ Column 1 repeats the estimates from Table 4 . Then, the results for dropping

\footnotetext{
${ }^{38}$ The GPA effect estimates are 0.212 and 0.195 for the subsamples of schools below and above the median share of students whose mothers have four year college degrees, respectively. Similarly, the first stage estimates for below and above median schools are 0.853 and 0.880 , respectively.

${ }^{39}$ When dropping observations where maternal education is missing, we only need to rerun the second stage because the relevant fixed effects for this sample are unaffected by dropping those individuals. On the other hand, when we use paternal education to replace missing maternal education, the fixed effect estimates will be affected so we rerun both the friendship link model and the IV model for grade point average. We follow this strategy through reestimating both stages when the sample or model is changing in a way that will alter the fixed effects, and only reestimating the second stage when the fixed effects are unchanged such as when we examine subsamples by type of school.
} 
observations if missing and for replacing maternal with paternal education if missing are shown in columns 2 and 3 of Panel 1. All results are robust, although the additional information provided by replacing maternal with paternal education when missing leads to a noisier, but larger effect size of maternal college friends for female students.

Next in Panel 2, we show the effects of changing the source of identifying variation by changing the fixed effects structure. As discussed above, we first estimate a triple difference model adding controls for student type by cohort fixed effects. These estimates are shown in column 1. Second, we change the demographic cell structure by adding a third variable for defining observationally equivalent students and then estimated fixed effects based on either race/ethnicitymaternal education-whether student was born in the U.S. and race/ethnicity-maternal educationwhether students resides with both parents cells. The results based on incorporating nativity into the cell structure are shown in column 2 , and the results using family structure are shown in column 3. The substantially more complex fixed effect structures of either the triple difference model or the expanded student type models yield very similar estimates for the effect of maternal college friends on female students, and as always all other estimated effects are statistically insignificant. ${ }^{40}$

In the last panel, we conduct three additional tests, which while intended to show robustness, also change the type of friendship effects for which we are testing. In the first column of Table 5 Panel 3, we present estimates based on friendship link and friendship effect on grade models that use any friendship referrals whether or not they are reciprocal. The results are robust, but the effect size is considerably smaller, consistent with one-way referrals representing friendships that are not as close and so possibly have less impact on outcomes. Next, in column

\footnotetext{
${ }^{40}$ Finally, we verify that our results for males and females are robust to estimating models where we control for multiple friendship variables using the same IV strategy. The maternal college friends effect is robust, and the other variables like total number of friends or number friend's of a specific race are not significant.
} 
2, we present results based on dropping all seventh and eighth grade students, as well as $9^{\text {th }}$ graders for the few high schools that are only $10^{\text {th }}$ through $12^{\text {th }}$ grade, from both the friendship link model and the GPA model rerunning those models for high school grades and students only. Again, results are robust. If anything, the results suggest that friendship effects on GPA are larger in the high school subsample. In both cases, there was no similar effect for men.

Finally, in column 3, we present estimates where the student race, ethnicity, parental education cells are based on paternal education, instead of maternal, when available, ${ }^{41}$ and reestimate the model. The estimated effects for paternal education are significantly smaller suggesting that maternal education is a much better proxy for the factors that influence friendship patterns along family socio-economic lines. This finding is consistent with earlier work that documents a relationship between the child's labor supply and both mother's labor supply and peer's mother's labor supply (Olivetti et al. 2013). Similarly, the estimates for males for paternal education are larger, but still noisily estimated so we cannot determine whether friend's paternal education affect boys' grades. The increase in point estimates when using paternal education reinforces our inability to make strong claims about whether friendships have effects on male students. $^{42}$

Finally, in the appendix, we present estimates where we instrument for multiple measures related to friendship composition within the same model. First, we include both number of maternal college and number of maternal no high school degree students in the same model, then we add and instrument for a control for the total number of friends and finally for controls for the

\footnotetext{
41 If paternal education is missing, we use maternal education as a proxy.

${ }^{42}$ We also examine models where we include weights based on one over the cohort size since the number of observations in the linked sample size is quadratic in the cohort size, but use of those weights has virtually no impact on our estimated effects of friendships in the second stage model.
} 
number of black and number of Hispanic friends. Our estimated effects of maternal education are robust across all models. Appendix Tables 7 presents the first stage estimates for the additional friendship variables, and Appendix Table 8 presents the instrumental variables estimates for these models. $^{43}$

\subsection{Friendship Effects versus Peer Environment Effects}

While we cannot prove that friendships drive our estimated effects, we provide some evidence concerning whether the effects appear to be attributable to friendships as opposed to other heterogeneous effects of peers. First, in Table 6, we allow average peer effects to vary by student type interacting the share of students in a cohort whose mothers have a college degree with maternal education, race and ethnicity. The friendship findings are robust. The strong positive effect of maternal college education friends for females remains and moderately increases, and the other effects remain small and insignificant. Only the interaction between student Hispanic and share maternal college is significant for girls with larger positive spillovers for Hispanic students, but the F-test on the full set of interactions is insignificant suggesting that these effects may have arisen from type 1 error. For boys on the other hand, the interaction between student black and share maternal college for men is negative implying smaller or even negative spillovers when compared to the average effect of peers presented in Appendix Table 6, and the F-test is highly significant. While not the topic of our paper, the cohort level positive peer effects of share maternal college students for boys appears concentrated among white and Hispanic students.

\footnotetext{
${ }^{43}$ In the model with all controls, total number of friends and number of black friends are statistically significant for males. However, the F-statistic for weak instruments is much smaller at 16, the two coefficients are positive correlated and have opposite signs, and both coefficients are smaller and insignificant when estimated without the other variable in the equation. This pattern at least raises concerns that these new results in the multivariate analysis are not reliable or robust.
} 
As a second attempt to address heterogeneous environmental effects, we examine whether the "direct environmental effect" associated with our female instrument can be found in the male sample - that is, if our instrument for female friendship patterns has more general, direct effects on own GPA other than friendship, one way to indirectly test for this is to examine whether the instrument also predicts GPAs for the males. ${ }^{44}$ We conduct this examination in two ways. First, we use the actual female instrument based on the composition of female students in each cohort to explain the GPA of boys and visa versa for girls' GPA. Second, we use the estimated link model fixed effects for female students with the male cohort composition to develop an instrument for boys' friendship composition and similarly only the female student fixed effects for predicting boys' friendships. In both cases, we do not find evidence that the girl's link model or girls' composition can explain the GPA of boys. For girls, however, we find that using the boys' fixed effects with girls' cohort composition has similar explanatory power to the models estimated above, likely because the friendship pattern fixed effects do not differ very much between boys and girls within the same school and the power of the instrument is primarily derived from variation in the cohort demographic composition. Regardless, the instrument that relies on the cohort composition of boys has no explanatory power for girls' GPA. ${ }^{45}$

These findings strongly suggest that our results are driven by the composition of potential friendship links that girls face within their cohort of grade mates, consistent with our estimates capturing the effects of friendship. Nonetheless, we cannot entirely rule out environmental factors that strongly correlate with the friendship environment. The environment could be shaped by simply having a lot of people around who would be good candidates to be friends with you. Such

\footnotetext{
${ }^{44}$ We thank Damon Clark for this suggestion.

45 These results are shown in Appendix Table A9.
} 
an environment might, for example, be a relatively safe environment even if you are not friends with these people.

\subsection{Mechanisms Analysis}

To investigate potential channels through which girls are affected by friends, we use the IV specification to examine non-cognitive outcomes. We manually classify variables into seven categories and use factor analysis procedures to generate composite variables. A high score reflects high self-evaluation or self-esteem, ${ }^{46}$ positive integration with the school social environment, ${ }^{47}$ good mental health, functioning well in school, ${ }^{48}$ more misbehavior, high frequency of smoking/drinking and good physical health respectively. ${ }^{49}$ The composite variables resulting from the principle components analyses are all standardized to have a variance of one. The individual components of each variable are shown in Appendix Table A10.

In Table 7, we present the results of our mechanisms analyses for females. Each column refers to a single outcome of interest, and each cell in Panel 1 represents the relevant coefficient of interest from a separate IV regression. The results suggest that female's subjective evaluation of the school environment and their integration into that environment are positively correlated with the expected number of high maternal education friends. The results indicate that girls with more friends whose moms graduate from college are to functioning well within the school getting along with others and participating in school. A one standard deviation on these variables implies approximately a one-quarter point increase in GPA. There are no statistically significant

\footnotetext{
${ }^{46}$ Self-evaluation includes whether the interviewees think themselves physically fit, are proud of themselves, like themselves, think they are doing things right, and try to study well. When discussed in Psychology, the concept of self-esteem can be either overall feeling about self or on a specific aspect, such as academic, appearance or popularity. It also can indicate troublesome behavior and depression (Rosenberg et al. 1989, Markowitz 2001).

${ }^{47}$ Environment evaluation shows the extent that students feel close, safe, fair and accepted at school.

${ }^{48}$ i.e. getting along with teachers and students, paying attention in school, and getting homework done.

${ }^{49}$ See Appendix A7.
} 
relationships with number of maternal college friends for male students, although the estimated effect of maternal college friends on functioning well in school is similar in magnitude to the statistically significant estimate for girls.

Our findings that girls are more influenced by high quality peers than boys on their integration with the school environment and their successful participation in that environment are consistent with the existing literature (Brown 1982, Griffin et al., 1999, Durlauf 2004). Numerous studies also have found that academic achievement and identification with school (which is similar to our measures of "environment") are positively correlated. For example, Akerlof and Kranton (2002) hypothesized that a sense of identification with the schooling process was the most likely explanation of the finding from Krueger and Whitmore (2001) that he impacts of small Kindergarten class size disappeared in middle school but re-emerged later with an increase in college going. ${ }^{50}$ Our analysis is novel because we have plausibly exogenous variation in friendship composition that can separate correlational and causal effects of peers. However, our analysis cannot establish the direction of the causal link between self-esteem and school achievement because we have only shown that friendship composition has a causal influence on both variables..$^{51}$

\subsection{Heterogeneity of Friendship Effects.}

We next examine how broad based these friendship effects for female students are. We start by looking across courses based on the GPA in the core areas of math, English, science and history. These estimates are presented in Table 8 where the estimates for girls are shown in Panel

\footnotetext{
${ }^{50}$ Fletcher (2009) tested this hypothesis but found no evidence with measures of participation in school clubs and activities.

${ }^{51}$ Most mechanism analyses of peer effects suffer from this problem including Bifulco, Fletcher and Ross (2011), Lavy and Schlosser (2011) and Carrell, Sacerdote and West (2013).
} 
1 , and the boys' estimates are shown in panel 2. With the exception of GPA in math courses, we find friendship effects for girls on all subjects. A lack of finding on math GPA is not entirely surprising because other papers have shown evidence that cognitive skills are more invariant to peers than non-cogitive skills (e.g. Kerr et al. 2013, Lavy and Sand 2018). We do not find any statistically significant effects for boys, and the point estimates are always smaller than the point estimates for girls. ${ }^{52}$

Then, we examine the effects for girl students by different types of schools splitting our sample based on the school having a share white above or below the sample median share white (64\%), being above or below the median share maternal college $(24 \%)$, and being above or below the median size (241 total students across the 6 grades). These estimates are shown in Table 9, and none of the differences between the subsample estimates are statistically significant. Moreover, the effect sizes are relatively similar across the samples with the exception of share white, but in that case the larger estimates for schools with above median share white are accompanied by a much larger standard error. Therefore, the statistical evidence for heterogeneity across schools is very weak.

Similarly, we find at most limited evidence of heterogeneity across types of girl students. Table 10 shows estimates for maternal college and maternal high school graduate students in columns 1 and 2, and estimates for white, black and Hispanic students in columns 3 through 5. The effect of friendships with maternal college students have a substantially larger point estimate for students whose mothers only have a high school degree, but the estimated difference between the maternal education subsamples is still less than a standard deviation. On race and ethnicity,

\footnotetext{
${ }^{52}$ Given the sizable estimate on paternal education for boys, we also estimated the models in Table 10 Panel 2 for boys using the paternal education based instrument. The estimates tended to be smaller than the robustness test estimates, and all estimated effects on subject GPA were insignificant for boys using paternal education.
} 
the estimated effects are larger for whites and Hispanics, but the standard errors in the race/ethnicity subsamples are very large. The inability to identify heterogeneity by race is not entirely surprising given that the identification strategy almost certainly relies heavily on the high levels of racial and ethnic homophile in friendship patterns.

\section{Conclusions}

This paper presents new evidence of the effects of the characteristics of friends on academic achievement. We use a novel strategy that leverages across-cohort, within school variation in the "supply of friend "types" and allows the impacts of the supply of friends to vary across schools. We then show that having friends with highly educated mothers is causally related to academic achievement for female students. The magnitude of these friendship effects suggest that increased friendship opportunities can explain approximately 38 percent of the estimated peer effects arising from an increase in the fraction of students in a cohort whose mothers have completed a four year college degree.

Naturally, we cannot rule out the possibility that some aspect of the school environment that promotes friendship between a student and student's whose mothers have a college degree also independently improves outcomes for that type of student. Therefore, a somewhat weaker conclusion is that peer environments that raise the likelihood of a student having friends with college educated mothers leads to an increase in girls' GPAs. However, our results cannot be explained by simple, school or grade/cohort level peer effects even when those effects are allowed to be heterogenous across students. Further, additional investigations show that the key factor that drives the significant estimate on number of maternal college students for girls is the composition of potential same cohort-same gender friends. 
To examine potential mechanisms, we show evidence that a friend's maternal education status is also linked to increases in both favorable opinions of and integration into the school environment, as well as student perceptions that they are functioning well in school in terms of getting along with teachers and other students and participating in their education. We also show that these effects are broad based arising in all subject areas examines other than math and appear to be relatively homogeneous across both types of students and types of schools.

\section{Acknowledgements}

The authors benefited from helpful suggestions by participants at seminars at University of Connecticut, University at Albany-SUNY, Federal Reserve Bank of Atlanta, and the NBER's Education Program and Children's Program Joint Meetings. We thank Edward Vytlacil, Ken Frank, Janet Currie, Caroline M. Hoxby, Kevin Lang, Damon Clark and David Frisvold for valuable comments.

\section{References}

Akerlof, George A., and Rachel E. Kranton. "Identity and schooling: Some lessons for the economics of education." Journal of economic literature 40, no. 4 (2002): 1167-1201.

Angrist, Joshua, Guido Imbens and Alan B. Krueger. "Jackknife instrumental variables estimation." Journal of Applied Econometrics 15, no. 1 (1999): 57-67.

Argys, Laura M. and Daniel I. Rees. "Searching for Peer Group Effects: A Test of the Contagion Hypothesis." Review of Economics and Statistics 90, no. 3 (2008): 442-58.

Bayer, Patrick, Stephen L. Ross and Giorgio Topa. "Place of work and place of residence: Informal hiring networks and labor market outcomes." Journal of Political Economy 116 (2008): 1150-1196. 
Babcock, Philip. "From Ties to Gains? Evidence on Connectedness and Human Capital Acquisition." Journal of Human Capital 2, no. 4 (2008): 379-409.

Ballester, Coralio, Antoni Calvó-Armengol and Yves Zenou. "Who's who in networks. wanted: the key player." Econometrica 74, no. 5 (2006): 1403-1417.

Bankston, Carl L. and Min Zhou. "Being Well vs. Doing Well: Self-Esteem and School Performance among Immigrant and Nonimmigrant Racial and Ethnic Groups." International Migration Review 36, no. 2 (2002): 389-415.

Bayer, Patrick, Hjalmarsson, Randi and David Pozen. "Building criminal capital behind bars: Peer effects in juvenile corrections." Quarterly Journal of Economics 124, no. 1 (2009):105147.

Bertrand, Marianne, Erzo Luttmer, and Sendhil Mullainathan. "Network Effects and Welfare Cultures." Quarterly Journal of Economics 115, no. 3 (2000):1019-55.

Bifulco, Robert, Jason M. Fletcher, and Stephen L. Ross. "The effect of classmate characteristics on post-secondary outcomes: evidence from the Add Health." American Economic Journal: Economic Policy 3, no. 1 (2011): 25-53.

Bifulco, Robert, Jason M. Fletcher, Sun Jung Oh and Stephen L. Ross. "Do classmate effects fade?" Labour Economics 29 (2014): 83-90

Billings, Stephen B., David J. Deming and Jonah E. Rockoff. "School Segregation, Educational Attainment, and Crime: Evidence from the End of Busing in Charlotte-Mecklenburg." The Quarterly Journal of Economics 129, no. 1 (2014): 435-476.

Billings, Stephen B., David J. Deming and Stephen L. Ross. Partners in Crime: Schools, Neighborhoods and the Formation of Criminal Networks. NBER Working Paper No. 21962 (2016). 
Black, Sandra E., Paul J. Devereux and Kjell G. Salvanes. "Under Pressure? The Effect of Peers on Outcomes of Young Adults" Journal of Labor Economics 31, no. 1 (2013): 119-53.

Blomquist, Sören and Matz Dahlberg. "Small sample properties of LIML and jackknife IV estimators: experiments with weak instruments." Journal of Applied Econometrics 14, no. 1 (1999): 69-88.

Bramoullé, Yann, Djebbari, Habiba and Bernard Fortin 2009. Identification of peer effects through social networks. Journal of Econometrics 150 (1): 41 - 55.

Brown, B. Bradford. "The extent and effects of peer pressure among high school students: A retrospective analysis." Journal of Youth and Adolescence 11, no. 2 (1982): 121-133.

Calvó-Armengol, Antoni, Eleonora Patacchini and Yves Zenou. "Peer effects and social networks in education." The Review of Economic Studies 76, no. 4 (2009):1239-1267.

Carrell, Scott E, Richard L. Fullerton and James E. West. "Does Your Cohort Matter? Measuring Peer Effects in College Achievement." Journal of Labor Economics 27, no. 3 (2009): 439464.

Carrell, Scott E., Bruce I. Sacerdote, and James E. West. "From Natural Variation to Optimal Policy? The Importance of Endogenous Peer Group Formation." Econometrica 81, no. 3 (2013): 855-882.

Chetty, Raj and Nathaniel Hendren. "The Impacts of Neighborhoods on Intergenerational Mobility I: Childhood Exposure Effects." NBER Working Paper No. 23001 (2016).

Chetty, Raj, Nathaniel Hendren, Lawrence F. Katz. "The Effects of Exposure to Better Neighborhoods on Children: New Evidence from the Moving to Opportunity Experiment." American Economic Review 106, no. 4 (2016): 855-902.

Clark, M.L. and Marla Ayers."Friendship Similarity During Early Adolescence: Gender and 
Racial Patterns." The Journal of Psychology 126, no. 4 (1992): 393-405.

Conger, Dylan. "Foreign-Born Peers and Academic Performance." Demography 52, no. 2 (2015): 569-592.

Durlauf, Steven N. "Neighborhood effects." In Handbook of Regional and Urban Economics Vol 4: Cities and Geography (Eds. J. V. Henderson and J. F. Thisse). Elsevier, New York, NY (2004): 2173-2242.

Farre, Lidia, and Francis Vella. "The intergenerational transmission of gender role attitudes and its implications for female labour force participation." Economica 80, no. 318 (2013): 219247

Fisman, Raymond, Sheena S. Iyengar, Emir Kamenica and Itamar Simonson. "Racial preferences in dating." The Review of Economic Studies 75, no. 1 (2008): 117-132.

Fletcher, Jason M. "Is identification with school the key component in the 'Black Box'of education outcomes? Evidence from a randomized experiment." Economics of Education Review 28, no. 6 (2009): 662-671.

Fletcher, Jason M., and Stephen L. Ross. "Estimating the effects of friends on health behaviors of adolescents." Health economics 27, no. 10 (2018): 1450-1483.

Friesen, Jane and Brian Krauth. "Ethnic enclaves in classrooms." Labour Economics 18, no. 5 (2011): 656-63.

Goodreau, Steven M., James A. Kitts and Martina Morris. "Birds of a feather, or friend of a friend? using exponential random graph models to investigate adolescent social networks." Demography 46, no. 1 (2009): 103-125.

Griffin, Kenneth W., Gilbert J. Botvin, Margaret M. Doyle, Tracy Diaz and Jennifer A. Epstein. "A six-year follow-up study of determinants of heavy cigarette smoking among high- 
school seniors." Journal of behavioral medicine 22, no. 3 (1999): 271-284.

Guryan, Jonathan, Kory Kroft and Matt Notowidigdo. "Peer effects in the workplace: Evidence from random groupings in professional golf tournaments." American Economic Journal: Applied Economics 1, no.4 (2009): 34-68.

Hanushek, Eric, John Kain and Steven Rivkin, "New Evidence about Brown v. Board of Education: The Complex Effects of School Racial Composition on Achievement" Journal of Labor Economics 27, no. 3 (2009): 349-383.

Haskell, Nancy L. "Overcompensating, For Better or For Worse: The Effects of Being Racially, Ethnically, and Socioeconomically Different from Your Peers." Working Paper (2015).

Haveman, Robert and Barbara Wolfe. "The determinants of children's attainments: A review of methods and findings." Journal of Economic Literature 33, no. 4 (1995): 1829-1878.

Hellerstein, Judith K, Melissa McInerney and David Neumark. "Neighbors and Coworkers: The Importance of Residential Labor Market Networks." Journal of Labor Economics 29, no. 4 (2011): 659-695.

Hoxby, Caroline. "Peer effects in the classroom: Learning from gender and race variation." NBER Working Paper 7867 (2000).

Jacob, Brian. "Public Housing, Housing Vouchers and Student Achievement: Evidence from Public Housing Demolitions in Chicago.” American Economic Review 94, no. 1 (2004): 233-58.

Pekkala Kerr, Sari, Tuomas Pekkarinen, and Roope Uusitalo. "School tracking and development of cognitive skills." Journal of Labor Economics 31, no. 3 (2013): 577-602.

Kling, J. R., J. B. Liebman and L. F. Katz. "Experimental analysis of neighborhood effects." Econometrica 75, no. 1 (2007): 83-119. 
Krueger, Alan B., and Diane M. Whitmore. "The effect of attending a small class in the early grades on college-test taking and middle school test results: Evidence from Project STAR." The Economic Journal 111, no. 468 (2001): 1-28.

Lavy, Victor and Edith Sand. "The Friends Factor: How Students' Social Networks Affect Their Academic Achievement and Well-Being?" NBER Working Paper 18430 (2012).

Lavy, Victor, and Edith Sand. "The Effect of Social Networks on Students' Academic and Noncognitive Behavioural Outcomes: Evidence from Conditional Random Assignment of Friends in School." The Economic Journal 129, no. 617 (2018): 439-480.

Lavy, Victor, M. Daniele Paserman and Analia Schlosser. "Inside the black-box of peer ability effects: Evidence from variation in high and low achievers in the classroom." Economic Journal 122 (2012): 208-237.

Lavy, Victor and Analia Schlosser. "Mechanisms and impacts of gender peer effects at school." American Economic Journal: Applied Economics 3, no. 2 (2011): 1-33.

Lichter, Daniel T. "Integration or fragmentation? Racial diversity and the American future." Demography 50, no. 2 (2013): 359-391

Ludwig, J., G. J. Duncan, L. A. Gennetian, L. F. Katz, R. C. Kessler, J. R. Kling and L. Sanbonmatsu. "Long-term neighborhood ełects on low-income families: Evidence from moving to opportunity." American Economic Review Papers and Proceedings 103, no. 3 (2013): 226-31.

Manski, Charles F. "Identification of endogenous social effects: The reflection problem." The Review of Economic Studies 60, no. 3 (1993): 531-542.

Manski, Charles F. Identification Problems in the Social Sciences. Harvard University Press, Cambridge, MA (1995). 
Manski, Charles F. "Economic analysis of social interactions." Journal of Economic Perspectives 14, no. 3 (2000): 115-136.

Markowitz, Fred E. "Modeling processes in recovery from mental illness: relationships between symptoms, life satisfaction, and self-concept." Journal of Health and Social Behavior 42 (2001): 64-79.

Marmaros, David and Bruce Sacerdote. "How do friendships form?" The Quarterly Journal of Economics 121 (2006): 79-119.

Mayer, Adalbert and Steven L. Puller. "The old boy (and girl) network: Social network formation on university campuses." Journal of public economics 92, no. 1 (2008): 329-347.

Mele, Angelo. "A structural model of segregation in social networks." Working Paper (2015).

Merlino, Luca Paolo, Max Friedrich Steinhardt and Liam Wren-Lewis. "More than Just Friends? School Peers and Adult Interracial Relationships." IZA Discussion Paper \#10319 (2016).

Moody, James. "Race, School Integration, and Friendship Segregation in America." American Journal of Sociology 107, no. 3 (2001): 679-716.

Mota, Nuno, Eleonora Patacchini, and Stuart S. Rosenthal. "Neighborhood effects, peer classification, and the decision of women to work." (2016). IZA discussion paper

Olivetti, Claudia, Eleonora Patacchini, and Yves Zenou. Mothers, friends and gender identity. No. w19610. National Bureau of Economic Research, 2013.

Oreopoulos, P. (2003). "The long-run consequences of living in a poor neighborhood." Quarterly Journal of Economics 118, no. 4 (2003), 1533-1175.

Patacchini, Eleonora and Yves Zenou. 2012. Juvenile delinquency and conformism. Journal of Law, Economics and Organization 28 (1): 1-31.

Rosenberg, Morris, Carmi Schooler and Carrie Schoenbach. "Self-esteem and adolescent 
problems: Modeling reciprocal effects." American Sociological Review 54 (1989): 10041018.

Ross, Stephen L. "Social interactions within cities: Neighborhood environments and peer relationships" In Handbook of Urban Economics and Planning (Eds. N. Brooks, K. Donaghy and G. Knapp). Oxford University Press, Oxford, England (2011).

Ross, Catherine E. and Beckett A. Broh. "The roles of self-esteem and the sense of personal control in the academic achievement process." Sociology of Education 73 (2000): 270-284.

Schmidt, Jennifer A. and Brenda Padilla. "Self-esteem and family challenge: An investigation of their effects on achievement." Journal of Youth and Adolescence 32, no. 1 (2003): 37-46.

Swenson, Lisa and Jonell Strough. "Adolescent's collaboration in the lassroom: Do peer relationships or gender matter." Psychology in the Schools 45, no. 8 (2008): 715-728.

Weinberg, Bruce A. "Group Design with Endogenous Associations." Regional Science and Urban Economics 43, no. 2 (2013): 411-21.

Weinberg, Bruce A. "Social interactions with endogenous associations." NBER Working Paper 13038 (2007).

Wong, Martha Suk Wai and David Watkins. "Self-esteem and ability grouping: A Hong Kong investigation of the big fish little pond effect." Educational psychology 21, no. 1 (2001): 79-87. 


\section{Appendix A: Derivation of Control Function for Omit-Self Bias}

A key problem that arises from the estimation of $\bar{p}_{x c S}^{y}$ from equation (2) in the main text to predict $p_{i x c s}^{y}$ is that the estimates only vary across cohorts for each type, $\overline{\mathrm{p}}_{x c s}^{y} \neq \overline{\mathrm{p}}_{x d s}^{y}$ where $\mathrm{c} \neq \mathrm{d}$, if the total number of students of type $y$ in school $s$ is not large; otherwise idiosyncratic variation will converge to zero and cohort composition will simply represent school composition as student population becomes large relative to the number of types. Therefore, while the total number of students of type $\mathrm{x}$ in the sample and the total number of students in any school or cohort may be relatively large, the number of students in each type in each school must be relatively small in order to create variation across cohorts. The dimensionality of our fixed effect vector increases linearly with the number of schools and the number of pair types, and so the school by student pair-type fixed effects suffer from an incidental parameters bias due to small numbers of observations in each cell. Specifically, the unobservable of a student $\mathrm{i}$ of type $\mathrm{x}$ in school s affects the estimates of $\widehat{\delta}_{\mathrm{xys}}$ for all types y and so the conditional expectation of the unobservable in the student outcome equation $\tau_{\text {ixcs }}$ is non-zero.

$$
\mathrm{E}\left[\tau_{\text {ixcs }} \mid \widehat{\delta}_{\mathrm{xys}} \forall \mathrm{y}\right] \neq 0
$$

In order to address this source of bias, we develop a cohort specific measure of predicted friendship outcomes that explicitly omits all students in the same cohort $c$ as student $i$ from fixed effect estimates. This correction is based on the logic of using jackknife instrumental variable estimators for small samples (Angrist, Imbens and Krueger 1999; Blomquist and Dahlberg 1999) that develop a prediction for each observation using the entire sample, except the observation itself, and comparable to, but more conservative than, the common practice of omitting an individual from the calculation of their peer averages. 
In mean differenced models, the standard approach to estimating the fixed effects is to back out those fixed effects by calculating the mean of the within cell residuals conditional on the cohort fixed effects $\pi_{c}$ in the non-differenced sample. The cohort specific fixed effect that omits student i's own cohort $\mathrm{c}$ can be estimated in the same way by summing the predicted residual over all cohorts $\mathrm{d}$ and pairs of students, $\mathrm{j}$ and $\mathrm{k}$ where $\mathrm{d} \neq \mathrm{c}$ as long as there exists at least one student of type $\mathrm{x}$ any cohort other than $\mathrm{c}$ in school $\mathrm{s}$.

$$
\hat{\delta}_{x y s}^{-c}=\sum_{\mathrm{d} \in\{e, s\}} e \neq c\left(\sum_{\mathrm{j} \in\{\mathrm{x}, \mathrm{d}, \mathrm{s}\}} \sum_{\mathrm{k} \in\{\mathrm{y}, \mathrm{d}, \mathrm{s}\}, \mathrm{k}<\mathrm{j}}\left(\mathrm{P}_{\mathrm{jkxyds}}-\hat{\pi}_{d}\right)\right) / N_{x y s}^{-c}
$$

where

$$
N_{x y s}^{-c}=\sum_{\mathrm{d} \in\{\mathrm{e}, \mathrm{s}\}} e \neq c\left(\sum_{\mathrm{j} \in\{\mathrm{x}, \mathrm{d}, \mathrm{s}\}} \sum_{\mathrm{k} \in\{\mathrm{y}, \mathrm{d}, \mathrm{s}\}, \mathrm{k}<\mathrm{j}} 1\right)
$$

The notation in equation (A2) is structured so that the first summation term sums over all cohorts in the school other than $\mathrm{c}$ in order to calculate a school level fixed effect, the second two term sum over all pairs of students $\mathrm{j}$ and $\mathrm{k}$ in the same cohort and of types $\mathrm{x}$ and $\mathrm{y}$ not allowing for student's to pair with themselves and not including duplicate pairs of $(\mathrm{j}, \mathrm{k})$ and $(\mathrm{k}, \mathrm{j})$.

Now based on equation (3), we define the individual specific prediction as

$$
\hat{P}_{x c s}^{y,-c}=\sum_{\mathrm{j} \neq \mathrm{i}, \mathrm{j} \in\{y, c, s\}}\left(\hat{\delta}_{x y s}^{-c}\right)
$$

However, as noted by Bayer, Ross and Topa (2008) and Guryan, Kroft and Notowidigdo (2009), this process creates a negative correlation within type-cohort-school because an individual's contribution to the fixed effect is eliminated for themselves and not for anyone else in the type-cohort-school. In Guryan et al.'s example, players select into golf tournaments, but are then randomly assigned to teams, which Guryan refers to as urns. The average team ability experienced by an individual golfer (omitting self) is negatively correlated (conditional on tournament fixed effects) with the individual's unobservable because within the tournament and urn the golfer cannot be paired with him/herself. Guryan et al. proposes a solution to this bias for 
peer composition or subgroup means, which is to include an additional control for peer composition at the higher tournament level of aggregation also omitting self. This control captures the negative correlation arising from omitting self and the estimates on the subgroup means are unbiased.

In order to apply the Guryan et al. logic to our example, it is useful to consider a slight generalization to their problem. Consider the following simple behavioral model

$$
y_{i c s}=\beta X_{c s}+\delta_{s}+\pi_{i c s}
$$

where $c$ is an urn and $s$ is a tournament. Assume that for any individual $i, X_{c s}$ is correlated with $\pi_{i c s}$, but can be divided into two additively separable components

$$
X_{c s}=X_{i c s}^{i}+X_{i c s}^{-i}
$$

where the first component contains the contamination that leads to the correlation and the second component is uncorrelated with $\pi_{i c s}$.

$$
\begin{aligned}
& E\left[\pi_{i c s} \mid X_{i c s}^{i}, \delta_{s}\right]=\alpha X_{i c s}^{i} \\
& E\left[\pi_{i c s} \mid X_{i c s}^{-i}, \delta_{s}\right]=0
\end{aligned}
$$

In Guryan et al., the second component $X_{i c s}^{-i}$ is equivalent to the average urn ability omitting self, and simply including this control will lead to biased estimates because $X_{i c s}^{i}$ is omitted and $X_{i c s}^{i}$ and $X_{i c s}^{-i}$ are correlated.

$$
E\left[y_{i c s} \mid X_{i c s}^{-i}, X_{i c s}^{i}, \delta_{s}\right]=\beta X_{i c s}^{-i}+\delta_{s}+E\left[X_{i c s}^{i} \mid X_{i c s}^{-i}, \delta_{s}\right]
$$

However, including both variables yields unbiased estimates since

$$
E\left[y_{i c s} \mid X_{i c s}^{-i}, X_{i c s}^{i}, \delta_{s}\right]=\beta X_{i c s}^{-i}+(\beta+\alpha) X_{i c s}^{i}+\delta_{s}
$$

The coefficient $X_{i c s}^{i}$ includes both the true effect and contamination allowing the estimate on $X_{i c s}^{-i}$ to be consistent. While the Guryan et al. idea of controlling for the tournament mean minus the individual's contribution seems intuitively appealing, the true source of the solution is that the 
within tournament variation in this mean nearly perfectly correlates with the individual, additively separable portion of the mean (the contaminated component) that has been removed from the variable of interest since after removing tournament fixed effects only the omission of the individual's own attribute remains in the variable.

In our context, students of a given type x sort into schools, but their allocation to a cohort or grade is assumed to be quasi-random. Therefore, the aggregate groups (or tournaments) are defined as type-school cells, and type-cohort-school cells are equivalent to one of Guryan et al.'s subgroups (or urns). We wish to separate the estimate of the predicted friendship outcome from equation (3) using all information $\hat{P}_{x c S}^{y}$ into a component that omits all information involving or influenced by choices made by individual i (omitting own cohort) and a second component that contains this contamination.

$$
\hat{P}_{x c s}^{y}=\hat{P}_{x c s}^{y,-c}+\underline{\hat{\mathrm{q}}}_{\mathrm{xcs}}^{\mathrm{y}}
$$

The expression $\hat{P}_{x c S}^{y,-c}$ has been constructed in equation (3) so that it does not contain any information from the choices of individual i and i's grademates, and differencing equation (3) from the actual fixed effect estimates yields $\hat{\mathrm{q}}_{\mathrm{xcs}}^{y}$ :

$$
\hat{\mathrm{q}}_{\mathrm{ics}}^{y}=\sum_{\mathrm{j} \neq \mathrm{i}, \mathrm{j} \in\{\mathrm{y}, \mathrm{c}, \mathrm{s}\}}\left(\widehat{\delta}_{\mathrm{xys}}-\widehat{\delta}_{\mathrm{xys}}^{-\mathrm{c}}\right)
$$

For our context, this contaminated component is equivalent to the control developed by Guryan et al. After the inclusion of tournament fixed effects, the Guryan et al. correction simply controls for the individual's contribution to their urn or team mean. The expression in (A12) contains the contributions of the choices made by all students in the individual student's cohort to the conditional mean or prediction for the student type by cohort by school cell to which the individual belongs. 